F. Reprod. Fert. (1975) 43, 233-239

\title{
ELECTROEJACULATION OF AUSTRALIAN MARSUPIALS AND ANALYSES OF THE SUGARS IN THE SEMINAL PLASMA FROM THREE MACROPOD SPECIES
}

\author{
J. G. RODGER AND I. G. WHITE \\ Department of Veterinary Physiology, University of Sydney, \\ New South Wales 2006, Australia
}

(Received 12th August 1974)

\begin{abstract}
Summary. Electroejaculation of a variety of Australian marsupials was attempted in this study. The animals used were conscious, sedated, anaesthetized or recently shot. Electroejaculation proved to be a satisfactory means of obtaining seminal plasma but not spermatozoa. The largest volumes of seminal plasma were collected from animals shortly after death. Anaesthetized animals also provided useful volumes of seminal plasma but only insignificant amounts were obtained from conscious and sedated animals.

Quantitative analyses of $\mathrm{N}$-acetylglucosamine, glucose and anthronereactive material were made of deproteinized, deionized, water extracts of seminal plasma from electroejaculates obtained from wallabies and kangaroos shortly after death. The major seminal sugar of the three macropod species was $\mathrm{N}$-acetylglucosamine and glucose was also present in quite large concentrations. These observations show that the pattern of sugars in the prostate gland of marsupials is reflected in the semen.
\end{abstract}

\section{IN'TRODUC'TION}

Fructose is the common sugar in the seminal plasma of many eutherians (see Mann, 1964), but analyses of the prostatic secretions of Australian marsupials suggest that, in macropods and possibly phalangers, glucose rather than fructose may be the major sugar (Rodger \& White, 1973, 1974a). The present paper describes attempts to collect semen from marsupials by electroejaculation with the aim of developing a convenient means of obtaining marsupial spermatozoa and seminal plasma for physiological and biochemical study. Biochemical analyses were carried out on the seminal plasma to determine if the pattern of sugars reported in the prostatic secretions was reflected in the semen.

Electroejaculation was first tried on a marsupial, the brush-tailed possum (Trichosurus vulpecula), by Howarth (1950) who used the hypodermic needlerectal probe method of Gunn (1936). The maximum amount of semen obtained was $31 \mathrm{ml}$ but the average volume was 5 to $10 \mathrm{ml}$; many motile spermatozoa were present in concentrations up to $1.36 \times 10^{8} / \mathrm{ml}$ (Howarth, 1950). A bipolar 
rectal probe was employed by Gilmore (1969) to obtain semen or urine from Trichosurus but this method was only successful for about half the animals. Both Howarth (1950) and Gilmore (1969) lightly anaesthetized their animals; the former used ether, the latter did not specify the anaesthetic employed. A similar bipolar electrode was used by Sadleir (1965) to collect semen from macropods within $5 \mathrm{~min}$ of death. Attempts to collect semen from long-nosed bandicoots (Perameles nasuta) by electroejaculation have failed (Bolliger, 1946; R. L. Hughes, personal communication). Table 1 summarizes the characteristics of the electrical stimuli applied by the various workers.

This paper reports the application of the bipolar rectal probe technique to conscious, sedated and anaesthetized specimens of tammar wallaby (Macropus eugenii), brush-tailed possum, long-nosed bandicoot and red kangaroo (Megaleia $r u f a$ ) and to recently shot specimens of tammar wallaby, grey kangaroo (Macropus giganteus) and red kangaroo. The sugar analyses were performed on seminal plasma collected from tammar wallaby, grey kangaroo and red kangaroo 5 to 15 min after death.

\section{MATERIALS AND METHODS}

Live specimens of tammar wallaby were obtained by trapping on Kangaroo Island, South Australia, and live specimens of long-nosed bandicoot and possum were trapped in the Sydney metropolitan area. Conscious specimens of red kangaroo were animals held at Taronga Zoological Park, Sydney. Specimens of red and grey kangaroos were shot in the Coonambie region of New South Wales during December 1972, and specimens of tammar wallaby were shot on Kangaroo Island during February 1973. All animals used were mature males.

Rectal probes were of the strip and ring electrode types. Opposite electrodes of the strip electrode probes and alternate rings of the ring probe were wired together. The smallest probe was used for bandicoots, the middle-sized probe for possums and wallabies and the largest probe for kangaroos (P1. 1, Fig. 1). Smaller probes were made of perspex and the largest made of PVC. In all cases, the electrodes were brass. The stimulator unit has been previously described (Martin \& Rees, 1962). Output from the stimulator could be varied between 0 and $10 \mathrm{~V}$; the frequency of the half-time square $D C$ pulses could be varied from 5 to 100 pulses/sec. Various combinations of voltage and frequency were tried but those listed in Table 1 proved most satisfactory. In the laboratory, ejaculates were collected into cut-down graduated centrifuge tubes (Pl. 1, Fig. 2 and Pl. 2, Fig. 3) and, in the field, into screw-top vials.

Animals were anaesthetized with halothane (Fluothane: I.C.I.). The halothane was vaporized by oxygen using a 'Fluotec' Mark II (Cyprane Ltd, England) vaporizer and an oxygen flow rate of 5 litres/min. The animals were first quietened with $2 \%$ halothane and, when relaxed, anaesthesia was induced by $4 \%$ halothane. Lower halothane concentrations failed to produce a depth of anaesthesia sufficient to restrain the animal when electrically stimulated. The halothane concentration was maintained at $4 \%$ for $10 \mathrm{~min}$, then reduced to zero when stimulation began. Attempts were made to compare the effects 
of tranquillizers with that of halothane. Acepromazine maleate (Acetylpromazine: Boots, total dose $1.4 \mathrm{mg} / \mathrm{kg}$ over $1 \mathrm{hr}$ ) and phencyclidine hydrochloride (Sernylan: Parke Davis, total dose $3 \mathrm{mg} / \mathrm{kg}$ over $1 \mathrm{hr}$ ) proved unsatisfactory; even at the quite high doses employed, tammar wallabies were still able to move around the room. Xylazine (Rompun: Bayer, total dose up to $4.5 \mathrm{mg} / \mathrm{kg}$ ) induced a degree of restraint similar to that from halothane anaesthesia. Acetyl-promazine and xylazine failed to restrain bandicoots.

Seminal plasma collected in the field was frozen in an insulated chest containing dry ice and kept frozen until extracts could be prepared in the laboratory. Coagulated seminal plasma (Table 2) was homogenized and deproteinized as described for prostatic tissue (Rodger \& White, 1974a).

Table 1. A summary of the characteristics of the electrical stimuli used to induce ejaculation by marsupials

\begin{tabular}{|c|c|c|c|c|c|}
\hline Reference & Species & $\begin{array}{l}\text { Voltage } \\
(V)\end{array}$ & $A C / D C$ & Frequency & Application of stimuli \\
\hline $\begin{array}{l}\text { Howarth } \\
\text { (1950) }\end{array}$ & $\begin{array}{l}\text { Trichosurus vulpecula } \\
\text { (brush-tailed possum) }\end{array}$ & 30 & $\mathrm{AC}$ & $50 \mathrm{c} / \mathrm{sec}$ & $\begin{array}{l}\text { Three } 10 \text {-sec shocks at } \\
\text { l-min intervals }\end{array}$ \\
\hline $\begin{array}{l}\text { Gilmore } \\
\text { (1969) }\end{array}$ & T. vulpecula & 12 & DC & $\begin{array}{l}75 \text { pulses/sec } \\
\text { (duration } 1.6 \\
\text { msec) }\end{array}$ & $\begin{array}{l}\text { On and off every few sec } \\
\text { till ejaculation or } \\
\text { urination }\end{array}$ \\
\hline $\begin{array}{l}\text { Sadleir } \\
\text { (1965) }\end{array}$ & $\begin{array}{l}\text { Macropus robustus (euro) } \\
\text { Megaleia rufa } \\
\text { (red kangaroo) }\end{array}$ & $10 \cdot 5$ & DC & & $\begin{array}{l}\text { Ten 2-sec shocks at 5-sec } \\
\text { intervals }\end{array}$ \\
\hline This study & $\begin{array}{l}\text { T. vulpecula } \\
\text { Macropus giganteus } \\
\text { (grey kangaroo) } \\
\text { Macropus eugenii } \\
\text { (tammar wallaby) } \\
\text { Megaleia rufa } \\
\text { Perameles nasuta } \\
\text { (long-nosed bandicoot) }\end{array}$ & 8 to $10^{*}$ & DG & $\begin{array}{l}35 \text { pulses/sec* } \\
\text { ( } \frac{1}{2} \text { time duration) }\end{array}$ & $\begin{array}{l}\text { Shocks of } 5 \text { sec were } \\
\text { delivered at } 10 \text {-sec intervals } \\
\text { until ejaculation, or until } \\
\text { it became obvious that no } \\
\text { response would occur }\end{array}$ \\
\hline
\end{tabular}

* The full range of voltage ( 0 to $10 \mathrm{~V}$ ) and frequency ( 5 to 100 pulses/sec) available from the stimulator were tried but those tabulated proved the most suitable.

The extracts were passed through a mixed bed of permutit resin (equal volumes of Zeo-Karb 225 and Deacidite FF) to remove ions that would interfere with subsequent paper chromatography and then freeze dried. The residue after freeze drying was dissolved in water, the volume depending upon the concentration of the substances assayed in the seminal plasma. This final water extract was frozen till analysed. The $\mathrm{N}$-acetylglucosamine was estimated as $\mathrm{N}$-acetylhexosamine by the modified Morgan-Elson method of Reissig, Strominger \& Leloir (1955) and N-acetylglucosamine standards. Glucose was determined by the glucose oxidase-Perid method (Boehringer Mannheim) of Werner, Rey \& Weilinger (1970) and anthrone-reactive sugar by the method of Brin (1966) with glucose standards. 


\section{Electroejaculation}

\section{RESULTS}

Ejaculates were collected from all species electrically stimulated except the bandicoot (five bandicoots were tested); good erections were obtained with the bandicoot but only traces of mucus came from the urethra. In all cases, conscious animals showed marked distress when electrically stimulated and the volumes of semen (four tammars: $0,0,0,0.2 \mathrm{ml}$; two red kangaroos: $0,0.2 \mathrm{ml}$; seventeen possums: mean $1.0 \mathrm{ml} \pm$ S.E. 0.52 , range 0 to $8.5 \mathrm{ml}$ ) were smaller than those obtained from anaesthetized or heavily sedated animals, except for the possum which produced a wide range of semen volumes. Two attempts were made to collect semen by electroejaculation from conscious red kangaroos but after extreme exertion by both the animals and attendants, only insignificant amounts of clear mucus were obtained.

With anaesthetized tammars, semen volume varied from 0 to $2.5 \mathrm{ml}$ (twenty five animals, mean $0 \cdot 88 \pm$ S.E. $0 \cdot 15$ ). When animals were stimulated to ejaculate shortly after death, large volumes of semen were obtained, e.g. twenty tammar wallabies, 10 to $20 \mathrm{ml}$, five red and six grey kangaroos, 5 to $10 \mathrm{ml}$.

Almost immediately after ejaculation, macropod semen coagulated to form a rubber-like mass (Pl. 1, Fig. 2 and Pl. 2, Fig. 3). Possum ejaculates varied in fluidity but did not clot in the manner observed for macropod ejaculates. All ejaculates were milky in appearance but this was not due to the presence of spermatozoa but to millions of spheres and globular bodies (Pl. 2, Fig. 4). These prostatic bodies were resistant to the osmotic shock of resuspension in distilled water and to the physical stress of homogenizing. Attempts were made to separate spermatozoa and prostatic bodies by centrifuging uncoagulated possum ejaculates at various speeds but, in all cases, the spermatozoa and the bodies remained associated. In most ejaculates, an examination of the sugars in the seminal plasma was made possible by the absence of spermatozoa which could presumably utilize the sugars and produce catabolic products or undergo breakdown in the extraction procedures. If spermatozoa had been present, their separation from the seminal plasma would have been made impractical by coagulation of the semen in the case of kangaroos and also by the close association of spermatozoa and prostatic bodies.

On a number of occasions in the present study, electroejaculation was attempted using a hypodermic needle as a flank electrode and a single rectal electrode. The hypodermic needle was placed both in the spinal area adjacent to the pelvis of the possum and in the ventral abdomen near the scrotum. The semen collected in this way was essentially similar to that obtained using the double-electrode rectal probe.

\section{Quantitative analyses of glucose and $\mathcal{N}$-acetylglucosamine in ejaculates}

Quantitative estimates of $\mathrm{N}$-acetyl amino sugar, glucose and anthronereactive material in seminal plasma collected from recently shot specimens of the three species are presented in Table 2. The mean figures for the three species indicate very similar levels of three parameters in the two kangaroos but higher levels of $\mathrm{N}$-acetylglucosamine and lower levels of glucose and anthronereactive material in the wallaby. 


\section{P.SIE 1}

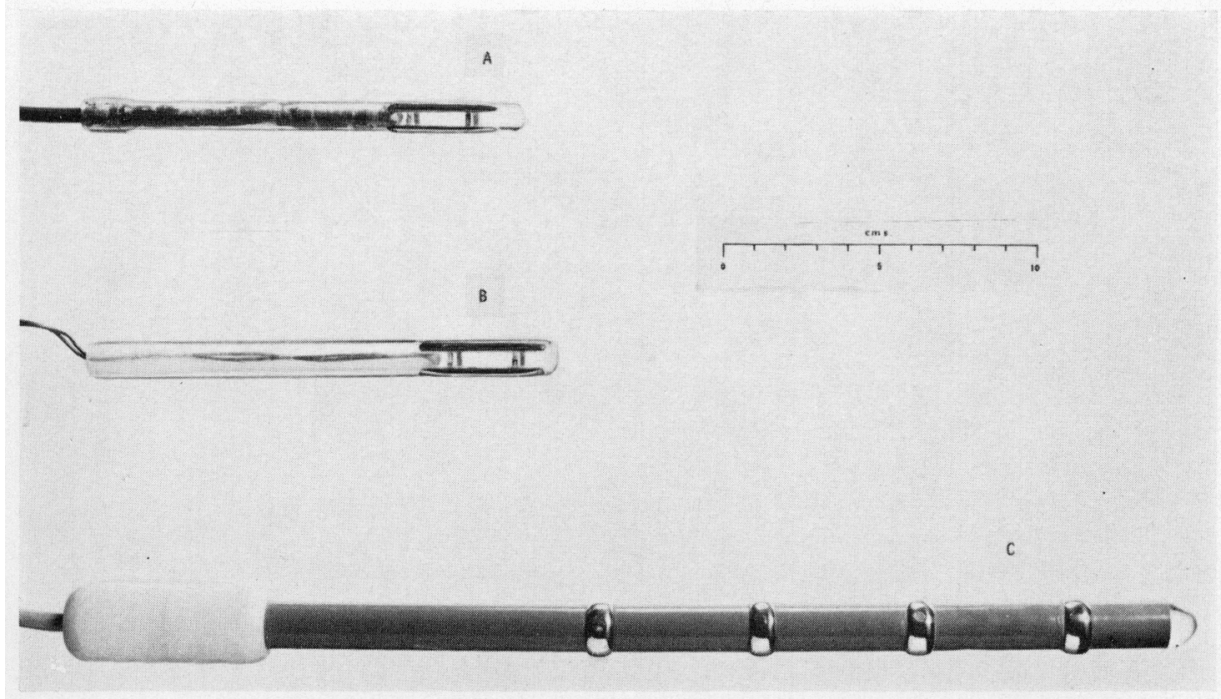

Fin. 1. The three rectal probes used in the study. The smallest probe (A) was used to induce ejaculation by bandicoots, probe $B$ was used for possums and wallabies and the largest probe (C) was used for kangaroos.

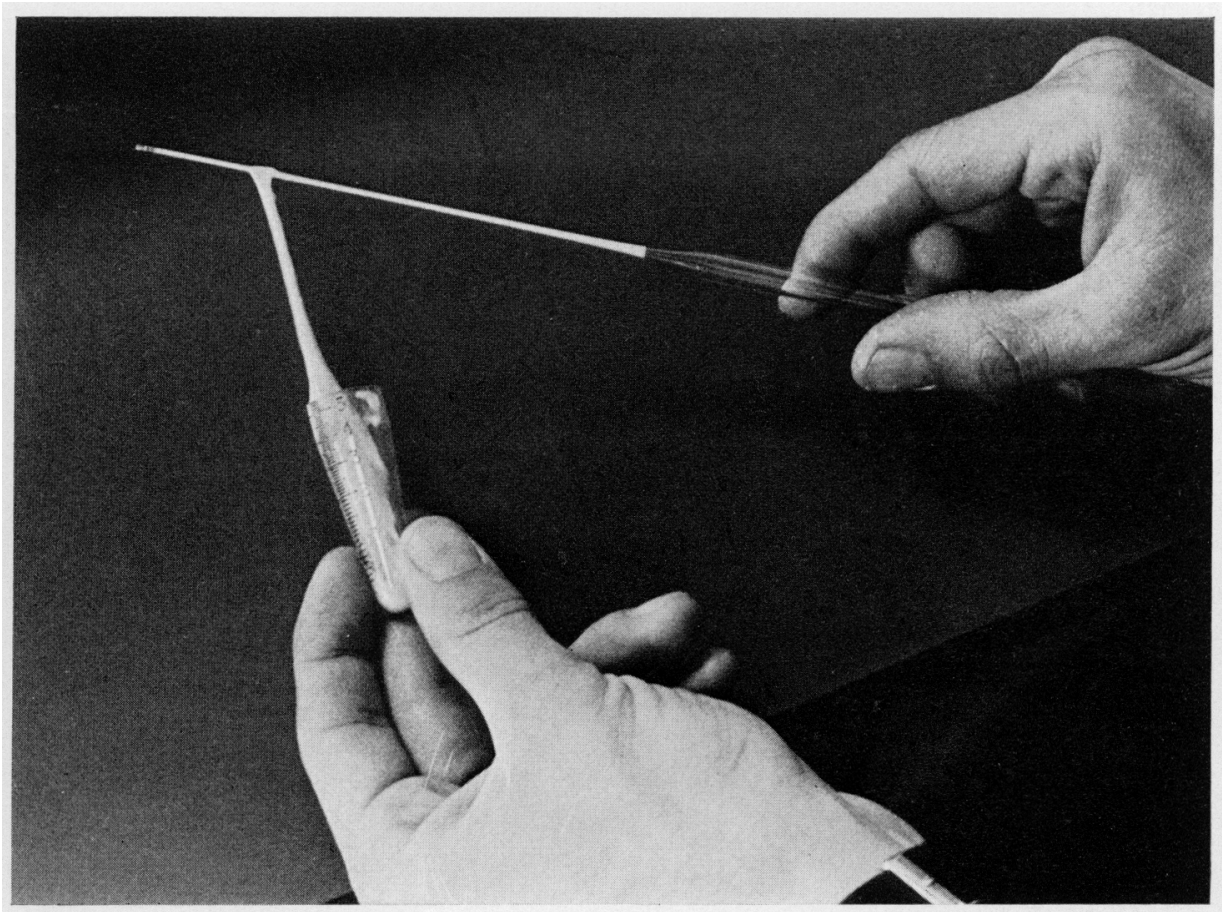

Fic: 2. An cjaculate from a tammar wallaby (.Macrofus eugenii) in the early stages of coagulation. 


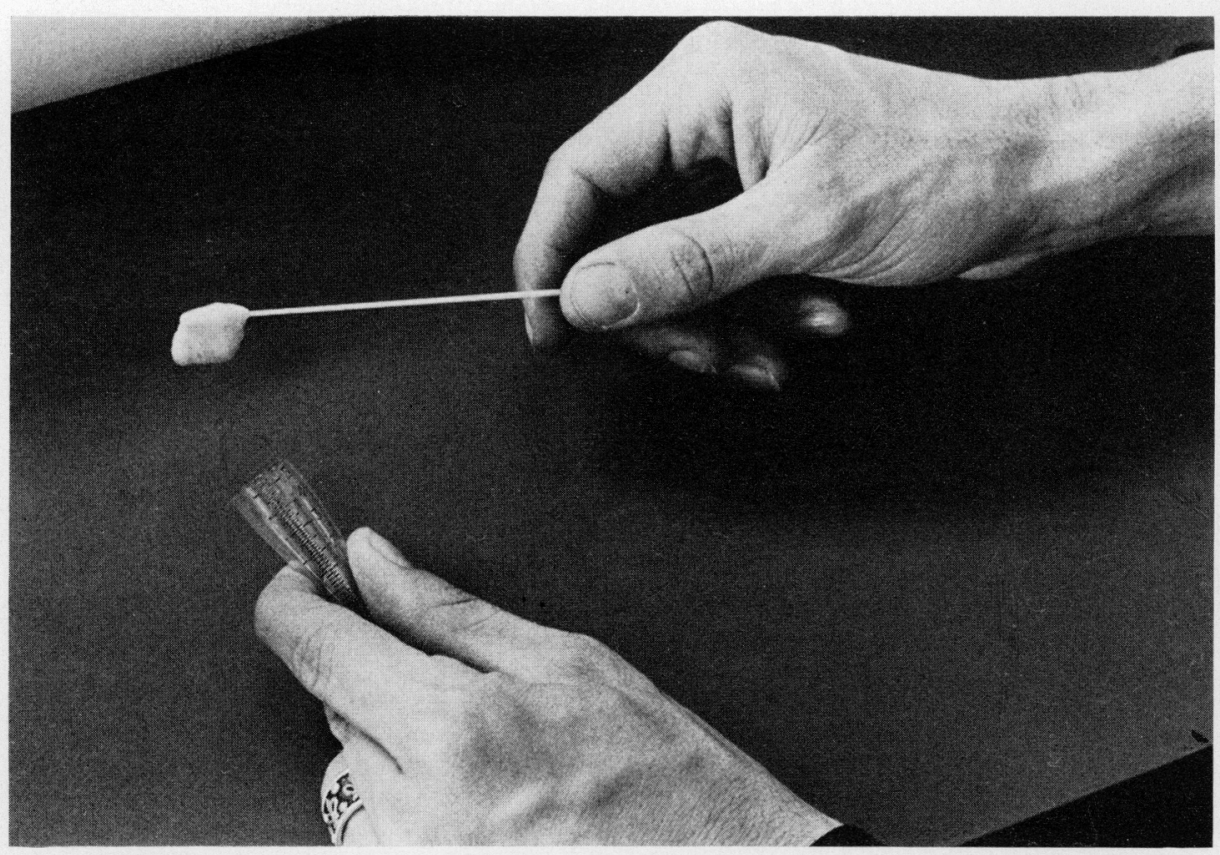

lise. 3. The same cjaculate as that shene in Pl. 1. The. 2 shomly alter the first photograph was taken. The ejaculate has become a rubbery mass.

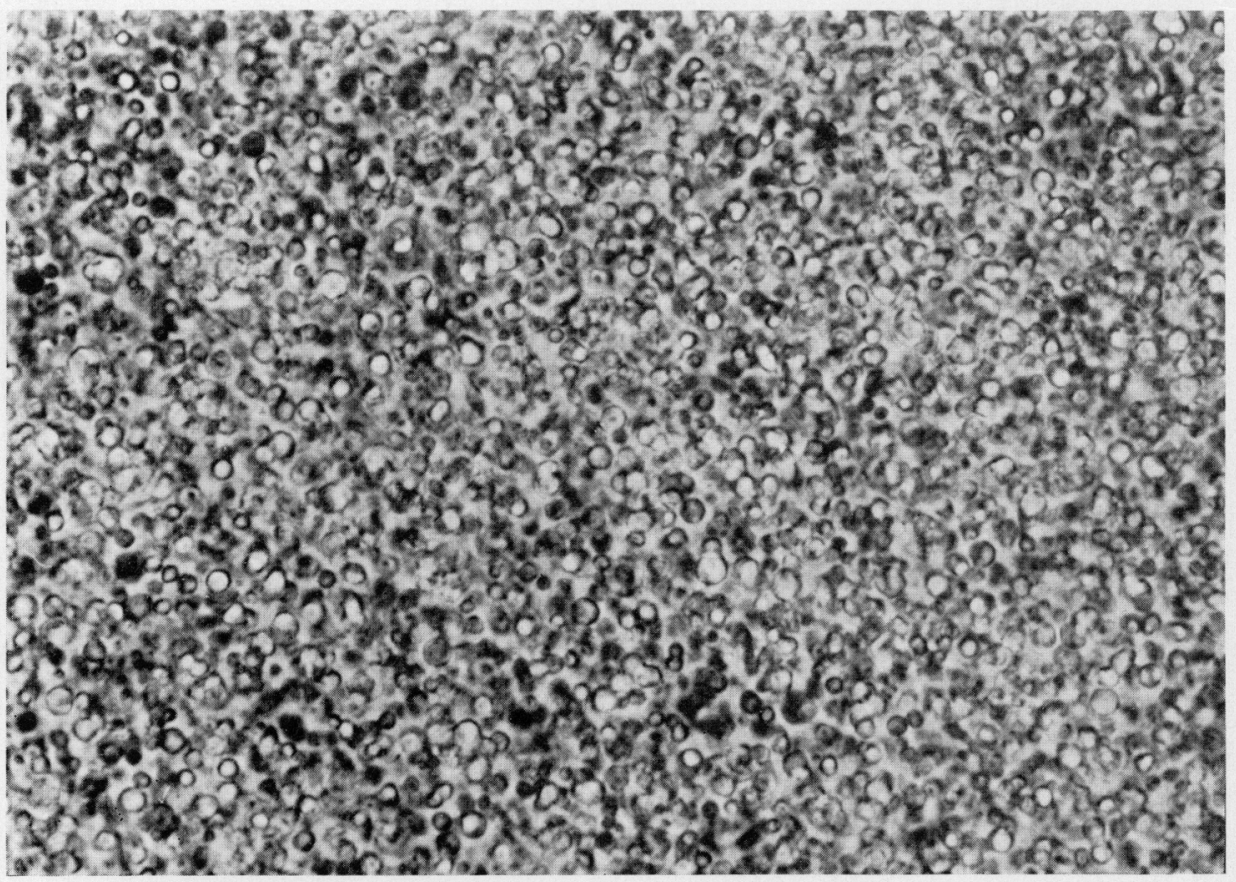

Fic. t. The spern-free cjaculate from a tammar wallaby (Macofus engenii), showing the many millions of prostatic bodies. $\times 400$. 
Table 2. Sugars ( $\mathrm{mg} / 100 \mathrm{~g}$ seminal plasma) in the seminal plasma of marsupials

\begin{tabular}{|c|c|c|c|c|c|}
\hline Species & $\begin{array}{l}\text { Animal } \\
\text { No. }\end{array}$ & $\begin{array}{c}\mathcal{N} \text {-acetylglucosamine } \\
(\text { Morgan-Elson reagent })\end{array}$ & $\begin{array}{c}\text { Glucose } \\
\text { (glucose oxidase) }\end{array}$ & $\begin{array}{l}\text { Anthrone-reactive } \\
\text { material }\end{array}$ & $\begin{array}{l}\text { Prostate } \\
\text { wt }(\mathrm{g})\end{array}$ \\
\hline Macropus eugenii & $\begin{array}{l}\text { ME } 306 \\
\text { ME } 309 \\
\text { ME } 311 \\
\text { ME } 312 \\
\text { ME } 313\end{array}$ & $\begin{array}{l}223.2 \\
105.1 \\
812.8 \\
507.9 \\
895.0\end{array}$ & $\begin{array}{l}34.0 \\
37.4 \\
14.8 \\
18.8 \\
39.5\end{array}$ & $\begin{array}{l}61 \cdot 5 \\
80.9 \\
66 \cdot 6 \\
59 \cdot 3 \\
63.0\end{array}$ & $\begin{array}{l}54 \cdot 9 \\
59 \cdot 2 \\
26 \cdot 4 \\
36 \cdot 1 \\
86 \cdot 1\end{array}$ \\
\hline Mean & & $508 \cdot 8$ & $28 \cdot 9$ & $66 \cdot 3$ & $52 \cdot 5$ \\
\hline Macropus giganteus & $\begin{array}{l}\text { MG } 1 \\
\text { MG } 2 \\
\text { MG } 4 \\
\text { MG } 5 \\
\text { MG } 6\end{array}$ & $\begin{array}{l}330 \cdot 6 \\
436 \cdot 7 \\
688 \cdot 7 \\
153 \cdot 8 \\
220 \cdot 8\end{array}$ & $\begin{array}{r}211.0 \\
90.9 \\
101.5 \\
76.5 \\
74.5\end{array}$ & $\begin{array}{l}305 \cdot 8 \\
137 \cdot 1 \\
147 \cdot 5 \\
112 \cdot 7 \\
120 \cdot 4\end{array}$ & $\begin{array}{l}34.9 \\
18 \cdot 6 \\
11.9 \\
39 \cdot 6 \\
52.9\end{array}$ \\
\hline Mean & & $336 \cdot 1$ & $110 \cdot 9$ & $164 \cdot 7$ & $31 \cdot 6$ \\
\hline Megaleia rufa & $\begin{array}{l}\text { MR } 1 \\
\text { MR } 2 \\
\text { MR } 3 \\
\text { MR } 4 \\
\text { MR } 5\end{array}$ & $\begin{array}{l}162 \cdot 7 \\
727 \cdot 0 \\
234.9 \\
696 \cdot 8 \\
175 \cdot 1\end{array}$ & $\begin{array}{r}80 \cdot 2 \\
103 \cdot 0 \\
88 \cdot 1 \\
74 \cdot 8 \\
61 \cdot 6\end{array}$ & $\begin{array}{r}102 \cdot 8 \\
196 \cdot 8 \\
127 \cdot 4 \\
146 \cdot 1 \\
91 \cdot 3\end{array}$ & $\begin{array}{l}\bar{Z} \\
\frac{24 \cdot 9}{52 \cdot 2}\end{array}$ \\
\hline Mean & & $399 \cdot 3$ & $81 \cdot 5$ & 132.9 & - \\
\hline
\end{tabular}

All results are the mean of two estimates on two separate homogenates of a single ejaculate from a single animal.

\section{DISGUSSION}

The method of electroejaculation as described in this study was a useful means of obtaining seminal plasma but not spermatozoa from phalangers and macropods, the largest volumes being obtained from animals shortly after death. Failure to obtain ejaculates with reasonable and consistent concentrations of spermatozoa at first caused concern, but close examination of the reports by earlier authors indicated results that were probably similar to those obtained in this study. Although Gilmore (1969) obtained spermatozoa in $50 \%$ of an unspecified number of semen or urine samples from possums, he gave no indication of the number of spermatozoa present. It is clear from the figures of Sadleir (1965) that at all times during the year there were wide variations in the concentration and total number of spermatozoa in kangaroo ejaculates and that some $(17 \%)$ were free of spermatozoa. His results, like those of the present study, indicate marked differences between individual breeding males in their response to electroejaculation. The relatively high sperm concentrations obtained by Sadleir in the semen from dead kangaroos were probably due to the low volumes of the ejaculates collected: mean volume for red kangaroo, approximately $0.5 \mathrm{ml}$, and for euro (Macropus robustus), approximately $2 \mathrm{ml}$ compared to 5 to $10 \mathrm{ml}$ for red kangaroos in this study. Howarth (1950) differed from all later workers in that he used alternating rather than direct current at higher voltages and therefore greater current flow. This may account for the higher sperm concentrations that he obtained compared to those in the present study. Collections from live tammar wallabies were made between November 1970 and May 1971 which would have included the February breeding season on Kangaroo Island. Possum ejaculates were collected between September 
and November 1971, and the best results were obtained in September at the end of the second breeding period (Pilton \& Sharman, 1962). The low volumes of ejaculates collected from the possums outside the breeding season would be consistent with data on seasonal variation in the weight of the prostate (Gilmore, 1969). Seasonal variation cannot, however, explain differences in the number of spermatozoa released because, even if the species is a seasonal breeder, the testes of the male do not undergo any significant changes in weight or spermatogenic activity throughout the year. The few exceptions include marsupial species not examined in the present study.

Most workers assume that ejaculation by marsupials is essentially similar to that by eutherians. In view of the continuous spermatorrhoea of $T$. vulpecula ( 1 to $10 \times 10^{6}$ spermatozoa/24 hr) and the long copulation time of some marsupials, however, true ejaculation, as observed in eutherians and lower vertebrates, may not occur in marsupials (Bolliger, 1946). The results presented here indicate that although there appears to be an ejaculation of prostatic secretion, release of spermatozoa may be controlled by another mechanism not affected by the electrical stimuli applied. The spermatozoa present in ejaculates obtained in this study and by earlier workers may be the result of spermatorrhoea and not of ejaculation. Even if ejaculates with high sperm counts can be obtained in the future, the study of the physiology of ejaculated marsupial spermatozoa will remain very limited unless coagulation can be prevented and the spermatozoa separated from the prostatic bodies.

In each species, there was considerable variation between ejaculates in the three sugars estimated. These differences did not appear to be related to the size of the prostate except perhaps in tammars in which glucose levels were lowest from animals with the smallest prostates. In both grey kangaroo and tammar wallaby, the results indicated the expected interrelationship between glucose and anthrone estimates, glucose being anthrone-reactive, while $\mathrm{N}$ acetylglucosamine was not.

The marked differences between the sugar concentrations in the seminal plasma of the tamar wallaby and grey kangaroo, and the similarity of the concentrations in the seminal plasma of the kangaroos is unexpected for, despite its smaller size, the tammar wallaby is much more closely related (same genus, Macropus) to the grey kangaroo than is the red kangaroo. The mean value for glucose and anthrone-reactive material in the seminal plasma of the kangaroos is remarkably similar to that in the posterior segment of the prostate of the red kangaroo, 136.2 and $92.2 \mathrm{mg} / 100 \mathrm{~g}$ tissue, respectively (Rodger \& White, 1974a). Glucose estimations confirmed the earlier inference (Rodger \& White, $1973,1974 a)$ that glucose was probably a major carbohydrate of marsupial semen, at least in macropods. The presence of non-anthrone-reactive Nacetylglucosamine in marsupial semen (Rodger \& White, 1974b) was not known at the time the prostatic tissue was examined (Rodger \& White, 1974a). The levels of glucose present in the marsupial semen would be quite sufficient to support glycolysis for some hours if the energy requirements of marsupial spermatozoa are of the same order as those of eutherian species.

The data presented in the present study, together with the earlier chromatographic data (Rodger \& White, 1974b), clearly indicate that $\mathrm{N}$-acetylgluco- 
samine is the major seminal sugar of the three macropod species examined and, possibly, of all Australian marsupials. Some suggestions have been made as to the rôle of the free N-acetylglucosamine (Rodger \& White, 1974b) but these remain speculative.

\section{ACKNOWLEDGMENTS}

The authors are indebted to Professor C. W. Emmens for his interest and advice. The New South Wales National Parks and Wildlife Service, Mr P. Davis, Brookland Park, Kangaroo Island, South Australia, and $\mathrm{Mr} \mathrm{T}$. Finnie, Taronga Zoological Park, Sydney, assisted in obtaining material. Mr D. Turner, Department of Veterinary Surgery, University of Sydney, assisted in the tranquillizer experiments. The work has been supported by funds from the Australian Research Grants Committee.

\section{REFERENCES}

Bolliger, A. (1946) Some aspects of marsupial reproduction. Proc. R. Soc. N.S.W. 80, 2-13.

Bris, M. (1966) Transketolase: clinical aspects. In Methods in Enzymology, Vol. 9, p. 506. Ed. W. A. Wood. Academic Press, New York.

GiLmore, D. P. (1969) Seasonal reproductive periodicity in the male Australian brush-tailed possum (Trichosurus vulpecula). F. Zool., Lond. 157, 75-98.

Guns, R. M. C. (1936) Fertility in sheep. Bull. Coun. sci. Ind. Res. Aust. No. 94.

Howarth, V. S. (1950) A method for the collection of the secretions of the individual accessory sex glands in a marsupial (Trichosurus vulpecula). Med. F. Aust. i, 566-567.

Mann, T. (1964) The Biochemistry of Semen and of the Male Reproductive Tract. Methuen, London.

Martin, I. C. A. \& Rees, D. (1962) The use of direct current pulses for the electroejaculation of the bull. Aust. vet. F. 38, 92-98.

Pilton, P. E. \& Sharman, G. B. (1962) Reproduction in the marsupial Trichosurus vulpecula. F. Endocr 25, 119-136.

Reissig, J. L., Strominger, J. L. \& Leloir, L. F. (1955) A modified colorimetric method for the estimation of N-acetylamino sugars. F. biol. Chem. 217, 959-966.

Rodger, J. C. \& White, I. G. (1973) Carbohydrates of the prostate of marsupials. F. Reprod. Fert. 32, $339-340$.

Rodger, J. C. \& White, I. G. (1974a) Carbohydrates of the prostate of two Australian marsupials, Trichosurus vulpecula and Megaleia nufa. F. Reprod. Fert. 39, 267-275.

Rodger, J. C. \& White: I. G. (1974b) Free N-acetylglucosamine in marsupial semen. J. Reprod. Fert. 39, 383-386.

SADLEIR, R. M. F. S. (1965) Reproduction in two species of kangaroo (Macropus robustus and Megaleia rufa) in the arid Pilbara region of Western Australia. Proc. zool. Soc. Lond. 145, 239-261.

WERNER, W., REY, H. G. \& WeILINGER, H. (1970) On the properties of a new chromogen for the determination of glucose in the blood according to GOD/POD method. Z. analyt. Chem. 252 224-228. 